\title{
Apontamentos sobre a mudança de posição da criança na sua travessia pela aquisição da escrita
}

\author{
Notes on the changing position of the child in its \\ crossing through the acquisition of writing
}

\section{Notas sobre el cambio de posición del niño en su recorrido por la adquisición de la escritura}

\footnotetext{
iD (9) Magda Wacemberg Pereira Lima Carvalho

Universidade Católica de Pernambuco (Unicap), Recife, Pernambuco, Brasil. E-mail: magdapcarvalho@hotmail.com.
}

\begin{abstract}
Resumo: Discutimos, neste artigo, o movimento de travessia da criança pela aquisição da linguagem escrita. Destacamos a visão estrutural da mudança conforme proposta da pesquisadora brasileira Cláudia de Lemos, no campo da aquisição de linguagem. Ampliando essa noção para a escrita inicial infantil, apresentamos os registros de uma criança de três anos de idade, acompanhada no Nível I da Educação Infantil. Observamos que, na passagem da criança de não-escrevente para escrevente, a letra propriamente dita aparece na escrita inicial quando a criança, colocada em contato com textos, movimenta-se na estrutura e recalca a representação pictórica.
\end{abstract}

Palavras-Chave: Aquisição da Escrita. Interacionismo. Mudança de Posição. Criança.

Abstract: In this article, we discuss the child's movement through the acquisition of written language. We emphasize the structural view of change as proposed by the Brazilian researcher Cláudia de Lemos, in the field of language acquisition. Extending this notion to children's early writing, we present the records of a three-year-old child, followed in Level 
I of Early Childhood Education. We observed that, in the child's transition from non-writer to writer, the letter itself appears in early writing when the child, placed in contact with texts, moves in the structure and represses the pictorial representation.

Keywords: Acquisition of Writing. Interactionism. Change of Position. Child.

Resumén: En este artículo, hablamos del movimiento de travesía del niño a través de la adquisición del lenguaje escrito. Destacamos la visión estructural del cambio propuesta por la investigadora brasileña Cláudia de Lemos, en el ámbito de la adquisición del lenguaje. Extendiendo esta noción a la escritura de la primera infancia, presentamos los registros de un niño de tres años, seguidos en el Nivel I de Educación Infantil. Observamos que, en la transición del niño de no escritor a escritor, la propia letra aparece en la escritura inicial cuando el niño, puesto en contacto con los textos, se mueve en la estructura y reprime la representación pictórica.

Palabras clave: Adquisición de la escritura. Interaccionismo. Cambio de posición. Niño.

Submetido em 01 de dezembro de 2020.

Aceito em 22 de fevereiro de 2021.

Publicado em 09 de agosto de 2021 
Apontamentos sobre a mudança de posição da criança na sua travessia pela aquisição da escrita Magda Wacemberg Pereira Lima Carvalho

\section{Introdução}

Pretendemos abordar a aquisição da linguagem escrita do ponto de vista estrutural da mudança, focalizando a travessia da criança pela escrita. De início, é importante destacar que empregamos o termo travessia por entendermos que, na aquisição da escrita, a criança faz passagem entre o desenho e a letra para tornar-se escrevente, quer dizer, a criança atravessa a linguagem escrita fazendo um movimento para frente e para trás, podendo ir do desenho para a letra e da letra para o desenho. Diante dessa compreensão, assumimos o interacionismo brasileiro, com especial atenção para a proposta da visão estrutural da mudança (2002).

Convém ressaltar que essa abordagem, ao considerar a aquisição de linguagem como resultado da mudança de posição do sujeito em relação ao outro, à língua e ao próprio sujeito (LEMOS, 2002), afasta a noção de aquisição como fenômeno cronológico regido por estágios de desenvolvimento para conceber a aquisição da linguagem como resultado das "mudanças que qualificam a trajetória da criança de infans a sujeito-falante" (LEMOS, 2002, p. 56). No caso da linguagem escrita, podemos dizer que, com fundamento em Burgarelli (2003), há mudanças que qualificam "a passagem da criança de não-escrevente a escrevente" (BURGARELLI, 2003, p. 25), além de apontar para a relação da criança com textos, ou meIhor, para a relação sujeito-língua. O que nos permite defrontar os diferentes estados ${ }^{1}$ de escrita presentes nas produções iniciais da criança.

Nesse sentido, a formulação teórica de Lemos, embora esteja voltada para a fala de crianças em aquisição de linguagem, apresenta-se como uma concepção que torna viável nossa tentativa de colocar em discussão o movimento de travessia da criança pela aquisição da linguagem escrita.

\footnotetext{
1 Empregamos o termo "estado" por compreendermos, com apoio em Saussure (2006), que essa palavra "evita fazer crer que ocorra algo semelhante na língua" (SAUSSURE, 2006, p. 118), quer dizer, evita que acreditemos que na escrita inicial infantil os registros da criança são sempre os mesmos.
} 
Apontamentos sobre a mudança de posição da criança na sua travessia pela aquisição da escrita Magda Wacemberg Pereira Lima Carvalho

Cabe realçar que nosso empreendimento, discutir a aquisição da escrita com base na visão estrutural da mudança, poderá incorrer no risco de limitar nosso estudo, mas assumimos esse risco por entendermos que o ponto de vista estrutural permite uma escuta singular para a mudança de estatuto da criança na escrita.

Assim, ao pensarmos a aquisição da escrita como uma travessia e observarmos que os primeiros registros escritos da criança são marcados pela presença de rabiscos, a questão que se colocou, inicialmente, foi: como os rabiscos dão lugar aos desenhos e estes às letras da língua constituída, e em que momento da travessia isso acontece?

No entanto, diante da concepção teórica que adotamos, reconhecemos que não é possível precisar o momento em que a letra gráfica emerge na escrita inicial, já que a travessia de cada criança é singular. Em face disso, reformulamos nossa questão, que passou a ser: como os rabiscos cedem lugar aos desenhos e estes à letra gráfica no movimento de travessia da criança pela aquisição da linguagem escrita?

Nossa suposição é que a letra propriamente dita aparece na escrita inicial quando a criança, capturada pelo funcionamento linguístico-discursivo da escrita, movimenta-se na estrutura e, com isso, recalca a representação pictórica.

Para um melhor entendimento acerca do recalque da representação pictórica e o aparecimento da letra gráfica recorremos a Gérard Pommier (2011), quando, ao destacar que "a passagem da imagem à letra é comandada pelo apagamento da imagem" (POMMIER, 2011, p. 19), esse autor propõe que a escrita é uma manifestação da operação do recalque ${ }^{2}$. Em outros termos, a escrita propriamente dita começa somente quando a virtude icônica se perde e a letra ganha possibilidade de significar.

Nesse aspecto, para que a criança escreva é necessário que ela seja colocada em contato com a escrita, pois, conforme o autor

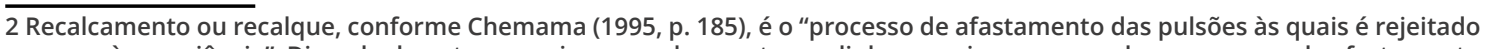
o acesso à consciência". Dizendo de outra maneira, o recalcamento, em linhas gerais, corresponde ao processo de afastamento de uma significação. 
Apontamentos sobre a mudança de posição da criança na sua travessia pela aquisição da escrita Magda Wacemberg Pereira Lima Carvalho

(1993), as crianças sozinhas não inventam a chave da escrita. Sendo assim, cabe ao outro (adulto), como representante do funcionamento da língua constituída, introduzir a criança na linguagem escrita, assumindo o papel de quem "se oferece ao mesmo tempo como semelhante e como diferente" (LEMOS, 1998, p. 17). Nesse sentido, ler para a criança, interrogá-la a respeito do que "escreveu" e escrever para que ela leia, de acordo com Lemos (1998), são atividades que contribuem para a inserção da criança na linguagem escrita.

A partir desse entendimento e com o intuito de preservar as bases da proposta que fundamenta nossa discussão, acreditamos que, para investigar o movimento de travessia da criança pela aquisição da linguagem escrita, é preciso seguir, também, a direção indicada por autores que revelam sua filiação à proposta de Lemos, como Sônia Borges (2006) e Zelma Bosco (2005; 2009), por exemplo, que compreendem a interação da criança com textos escritos como indispensável para a aquisição da escrita.

Nessa perspectiva, reconhecemos a necessidade de apresentar alguns pontos relevantes da proposta que baseia nossas reflexões. Passemos a esses pontos.

\section{O interacionismo brasileiro e a visão estrutural da mudança}

Para tratar da aquisição de linguagem a partir do interacionismo brasileiro, proposto por Lemos, é importante ressaltar que essa proposta não trata da interação propriamente dita, mas da relação entre enunciados, ou seja, trata de um trabalho da linguagem sobre a própria linguagem. Isso porque a relação entre a criança e o outro-falante, para essa perspectiva teórica, assinala a condição da criança como intérprete do outro, de si própria e da linguagem.

Convém dizer que a tentativa de identificar o percurso linguístico da criança é marcada por impasses e reformulações dessa 
Apontamentos sobre a mudança de posição da criança na sua travessia pela aquisição da escrita Magda Wacemberg Pereira Lima Carvalho

proposta, isso em razão de a fala inicial colocar a autora diante de "um processo que se repete sob a forma de mudanças na relação da criança com a língua" (LEMOS, 2000, p. 54), isto é, na relação sujeito/língua. No entanto, como a noção que adotamos é a da visão estrutural da mudança de posição, não nos debruçaremos sobre formulações anteriores, embora seja imprescindível ressaltar que, desde o início de suas reflexões teóricas, Lemos tomou o diálogo "como unidade de análise e, ao mesmo tempo, como lugar de inserção da criança na linguagem" (LEMOS, 1989, p. 3).

Nesse sentido, a observação de como a fala infantil se constitui ao longo da aquisição fez com que a autora (2000) compreendesse a fala da criança como imprevisível e heterogênea e, por isso, impossível de ser descrita em categorias linguísticas, visto que fragmentos da fala do outro comparecem na fala da criança como enunciados atípicos.

Diante disso, Lemos (2000; 2002) questiona o fato de a criança ao falar ser falada pelo outro e, também, o afastamento da fala do outro apontado pelos "erros" que emergem na fala da criança, erros estes entendidos pela autora como indícios de não-saber, ou melhor, como "erros insólitos, imprevisíveis, assistemáticos que mostram uma face inaudita da língua" (LEMOS, 2000, p. 58) e que podem ser compreendidos como uma relação entre saber e falta. Com isso, a autora passa a interrogar o efeito da fala do outro na fala da criança e a escuta da criança a sua própria fala, com destaque para a necessidade de explicar a "passagem da fala da criança enquanto fala não-analisada do outro para uma fala articulada" (LEMOS, 1999, p. 13), pois, em seu entendimento,

tratar a fala da criança como evidência empírica de um conhecimento definido quer como inato e deflagrado pelo input, quer como construído por um sujeito epistêmico diante da língua como objeto, quer como construído na interação com um outro mediador da relação com esse objeto, resulta na eliminação disso que a fala da criança revela. A saber, que nela a língua, o outro e o próprio sujeito que emerge dessas relações estão es- 
Apontamentos sobre a mudança de posição da criança na sua travessia pela aquisição da escrita Magda Wacemberg Pereira Lima Carvalho

truturalmente vinculados. Isto é, não podem ser tomados como instâncias independentes, unidirecionalmente ordenáveis, como implicado na atribuição ao outro do papel de mediador ou na atribuição à fala do outro de um estatuto de input. (LEMOS, 2000, p. 59).

Nessa perspectiva, o plano teórico de Lemos, apoiado na linguística estruturalista europeia e na psicanálise lacaniana, concebe a "criança como capturada por um funcionamento linguístico-discursivo que não só a significa como Ihe permite significar outra coisa, para além do que a significou" (LEMOS, 2002, p. 55), dizendo melhor, o interacionismo proposto por essa autora compreende o sujeito como "capturado" pela linguagem e submetido ao seu funcionamento. No entanto, não se pode deixar de salientar que devido ao retorno de fragmentos da fala do outro na fala inicial, a criança é considerada, nessa proposta, como alienada à fala do outro, quer dizer, o aparecimento de parte da fala do outro na fala da criança possibilita a compreensão dessa fala nascente como referida à fala do outro. Nesse sentido, um ponto que nos chama atenção é que ao mesmo tempo que a fala inicial aparece como alienada à do outro também parece distanciar-se, especialmente, quando o erro comparece na fala da criança e esta, mesmo depois de ouvir a correção feita pelo outro, volta a repetir o erro, colocando, dessa forma, a fala inicial como "impermeável à correção do adulto" (LEMOS, 2000, p. 58), impossível de regularizar ou de colocar em categorias.

Desse modo, as produções estranhas que irrompem nessa fala são entendidas como indicativo da discordância entre o que a criança enuncia e o que ela escuta como erro em sua própria produção. Nesse sentido, a autora questiona:

Se, de um lado, a heterogeneidade e a imprevisibilidade dessa fala não permite uma descrição em termos de categorias linguísticas e se, de outro, as mudanças que nela se fazem ver concernem sua relação com a fala do outro e com a escuta da própria fala pela criança, o que está realmente em jogo quando se fala em mudança? (LEMOS, 2000, p. 59). 
Apontamentos sobre a mudança de posição da criança na sua travessia pela aquisição da escrita Magda Wacemberg Pereira Lima Carvalho

Como resposta a esse questionamento, Lemos diz que a proposta que tem em mente é a de uma estrutura cujos polos "onde se define a mudança - correspondem concepções do outro e da relação do sujeito com a língua, assim como do próprio sujeito" (LEMOS, 2000, p. 60). Nessa direção, a autora traz para o campo de estudos da aquisição de linguagem uma compreensão completamente distinta de linhas como a gerativista e a interacionista, por exemplo, em que a primeira é centrada nas propriedades estruturais da língua e a segunda na interação entre a criança e o adulto.

Nesse aspecto, parece importante convocar mais uma vez as palavras da autora para reiterar que sua proposta rejeita a ideia de desenvolvimento, pois "a noção de estrutura repele a ideia de ordenação em estágios e sua superação, deslocando a noção de mudança para a de dominância de um dos polos em uma determinada posição" (LEMOS, 2000, p. 60).

Para um melhor entendimento acerca dessa concepção, fazemos apelo ao texto Das vicissitudes da fala da criança e de sua investigação (2002) em que a autora esclarece seu pensamento e exemplifica as mudanças de posição da criança na língua, com base em alguns episódios de fala. Essas mudanças se dão a partir do efeito do funcionamento da língua, isto é, a partir não da descrição dos enunciados, mas "pelos processos metafóricos e metonímicos" (LEMOS, 2002, p. 56), conforme formulação do linguista Roman Jakobson ${ }^{3}$. A esse respeito, cabe realçar que, desde o texto Los procesos metafóricos y metonímicos como mecanismos de cambio (1992), Lemos traz para suas discussões a reflexão jakobsoniana sobre o funcionamento linguístico. Isso em razão de a proposta desse linguista conceber a linguagem de um ponto de vista funcional a partir da redimensão dada às relações in praesentia e in absentia da elaboração saussuriana, quando, ao acrescentar as ideias de combinação e substituição a essas relações, Jakobson pode associá-las à metonímia e à metáfora. Em vista disso, o reconhecimento da metáfora e da metonímia como eixos de elaboração do discurso

3 A proposta de polos metafórico e metonímico é apresentada por Jakobson no texto Dois aspectos da linguagem e dois tipos de afasia (2008). 
Apontamentos sobre a mudança de posição da criança na sua travessia pela aquisição da escrita Magda Wacemberg Pereira Lima Carvalho

permite observar e explicar a linguagem em funcionamento, no que se refere à sua constituição e dissolução.

A partir desses dois eixos de elaboração do discurso, a autora apresenta uma proposta que envolve a noção saussuriana de língua como sistema e que permite observar o funcionamento da língua na fala de crianças, especialmente o comparecimento de fragmentos da fala do outro na da criança, bem como os "erros" que emergem nessa fala. Com isso, essa proposta concebe uma escuta singular à fala inicial.

Sobre os polos da estrutura, Lemos propõe como primeiro polo a posição marcada pela dominância da fala do outro, o segundo pela dominância do funcionamento da língua e o terceiro pela relação da criança com sua própria fala. Para exemplificar essa tese, a autora (2000; 2002) apresenta os seguintes episódios:

\section{Primeira posição:}

A criança, C., e a mãe, M., estão folheando uma revista:

C.: ó nenê/ o auau

M.: Auau? Vamo achá o auau? Ó, a moça tá tomando banho.

C.: ava? Eva?

M.: É. Tá lavando o cabelo. Acho que essa revista não tem auau nenhum.

C.: auau

M.: Só tem moça, carro, telefone.

C.: Alô?

M.: Alô, quem fala, é a Mariana?

(C. $1 ; 2.15)$ 
Apontamentos sobre a mudança de posição da criança na sua travessia pela aquisição da escrita Magda Wacemberg Pereira Lima Carvalho

\section{Segunda posição:}

A mãe, M., e menina, C., estavam jogando bola, a criança faz muito barulho e a mãe a repreende dizendo que ela vai acordar a vizinha, Flávia, que está dormindo:

M.: Esta bola faz muito barulho.

C.: A Fávia é nananda.

M.: É, a Flávia está nanando e você fica fazendo barulho.

(C. $1 ; 9,15)$

\section{Terceira posição:}

Uma amiga da mãe da criança, T., riscou no chão um quadro para brincar de amarelinha com a criança, C., mas um dos quadros não foi riscado:

C.: Quase que você não fez a amarelinha.

T.: O que, Verrô?

C.: Faz tempo que você não fez a amarelinha sua.

T.: O que, Verrô? Eu não entendi.

C.: Está faltando quadro na amarelinha sua.

(C. $4 ; 0.18)$

Do ponto de vista estrutural, o que interessa no episódio indicativo da primeira posição "é a escuta da fala da mãe que se revela na fala da criança" (LEMOS, 2002, p. 58), pois ao recortar do enunciado da mãe o significante "telefone" para daí convocar "alô", a criança mostra-se alienada à fala da mãe. Dizendo melhor, a criança por estar referida à fala do outro traz para a cena enunciativa um significante ausente, mas que tem relação associativa com o que foi falado pelo outro. Diante disso, é possível compreender a 
Apontamentos sobre a mudança de posição da criança na sua travessia pela aquisição da escrita Magda Wacemberg Pereira Lima Carvalho

dominância do polo do outro como uma posição em que a criança, alienada ao outro, pode trazer para sua fala recortes de situações anteriores, não só episódios de fala do outro, mas também "estados de coisa no mundo" (LEMOS, 2000, p. 62) como o ruído da chave na fechadura de uma porta ou o barulho do motor de um carro conhecido, por exemplo.

No que se refere à segunda posição, polo cuja dominância é a língua, a autora diz que o funcionamento da língua é "apreensível através do fenômeno tratado como erro ou violação das leis e normas da língua" (LEMOS, 2000, p. 63). Em outros termos, o "erro" que surge na fala da criança assinala a relação entre saber e falta e, desse modo, se dá como diferença em relação à fala do outro, que conhece e domina a língua constituída.

Para a autora (2000), o "erro" dá a ver as relações entre significantes que circulam na fala da criança. Desse modo, o enunciado "A Fávia é nananda" é entendido como um movimento que denota o afastamento do enunciado da mãe, isso porque a substituição de "está nanando" por "é nananda" marca a "relação com uma rede de cadeias latentes, do tipo é bonita/está bonita, é bonito/ está bonito" (LEMOS, 2000, p. 65). Dessa forma, a segunda posição é marcada por deslocamentos e construções associativas de significantes já conhecidos pela criança.

As tentativas de reformulação do enunciado, pela criança, na cena que exemplifica a terceira posição na estrutura quando o polo dominante é o sujeito, "mostram algo mais do que a possibilidade da criança escutar na fala do outro uma interrogação sobre sua fala, sobre uma diferença que produz um estranhamento" (LEMOS, 2000, p. 68-69), quer dizer, as tentativas de reorganização do enunciado mostram que a criança, nessa posição, escuta sua própria fala e, por isso, pode retomá-la e reformulá-la reconhecendo a diferença entre sua fala e a do outro.

De acordo com Lemos (2000), a substituição de "quase que" por "faz tempo que" e, deste, por "está faltando" aponta para a escuta da criança sobre sua própria fala, pois, nessa posição, a 
Apontamentos sobre a mudança de posição da criança na sua travessia pela aquisição da escrita Magda Wacemberg Pereira Lima Carvalho

criança não só reconhece o "erro" em sua produção como substitui expressões que mantém relação com o que ela quer dizer. Nesse sentido, o que se apresenta como relevante para a compreensão do que Lemos propõe como terceira posição é o reconhecimento da criança da diferença entre as expressões que ela usa na tentativa de produzir seu enunciado.

Diante disso, entendemos que a perspectiva estrutural da mudança de posição, ao permitir notar a mudança de estatuto da criança de não falante para falante, mostra-se como uma importante proposta para a compreensão da aquisição de linguagem, o que nos faz considerar essa visão como uma possibilidade teórica para investigar, também, a mudança da criança de não-escrevente para escrevente, conforme veremos.

\section{A passagem do desenho à letra e a mudança de posição da criança na escrita}

Ao propormos a visão estrutural da mudança para investigar a aquisição da linguagem escrita, embora nossa discussão aparente uma busca por equivalência entre as três posições, propostas por Lemos (2000), esclarecemos que nosso objetivo não é emoldurar a escrita inicial da criança em quadros classificatórios, mas refletir acerca da mudança de posição da criança na estrutura, em sua travessia pela aquisição da escrita, visto que o movimento feito pela criança para chegar até a escrita da letra propriamente dita parece ter relação ora com a escrita do outro, ora com o funcionamento da língua, ora com o próprio sujeito.

Nesse sentido, tratar a aquisição da escrita como mudança exige a compreensão de que o movimento feito pela criança na estrutura é o que merece destaque, uma vez que não há superação de nenhuma das posições e nem progressão por fases ou estágios. Nessa perspectiva, para que a criança escreva é necessário que ela seja colocada em contato com a escrita, pois, como disse Pommier (1993), as crianças sozinhas não inventam a chave da escrita. 
Apontamentos sobre a mudança de posição da criança na sua travessia pela aquisição da escrita Magda Wacemberg Pereira Lima Carvalho

Para Borges (2006), o acesso da criança à escrita implica a representação, ou seja, a criança precisa ser colocada em situações de leitura e escrita, em virtude de que no movimento inicial de travessia pela aquisição da linguagem escrita

é preciso que a criança represente a língua escrita ainda que pela (re) constituição de um simulacro conferindo-Ihe estabilidade, ainda que imaginária. Nesse sentido, escrever, para a criança, é essencialmente uma atividade de imitação das representações do que é "possível" na escrita. (BORGES, 2006, p. 98).

Nessa direção, a partir do que a criança registra como escrita, na folha de papel, é possível concebermos uma escuta singular à aquisição da linguagem escrita, visto que o registro de cada criança é único. Desse modo, para que possamos observar o movimento de travessia da criança pela aquisição da linguagem escrita, tendo como fundamento a noção estrutural da mudança de posição, apresentamos, neste momento, quatro cenas de escrita protagonizadas por uma criança de três anos, que chamaremos de M., acompanhada durante seu primeiro ano escolar, no Nível I da Educação Infantil4:

\section{Cena 1}

O texto a seguir foi produzido após a leitura do conto "A Bela Adormecida", em que as crianças da turma foram convidadas a escrever a narrativa lida. Para isso, elas receberam folhas impressas contendo algumas imagens que ilustravam o conto. Convém destacar que no momento da escrita as crianças já conheciam as diferentes formas gráficas da letra "A". Vejamos:

4 Requisitos éticos - CAAE № 80985617.9.0000.5206. Importa ressaltar que a Escola onde os dados foram coletados incentiva a escrita com letras desde o Nível I da Educação Infantil, cujas crianças matriculadas têm, no mínimo, três anos de idade. 
Apontamentos sobre a mudança de posição da criança na sua travessia pela aquisição da escrita Magda Wacemberg Pereira Lima Carvalho

Figura 1 - Escrita com traçados

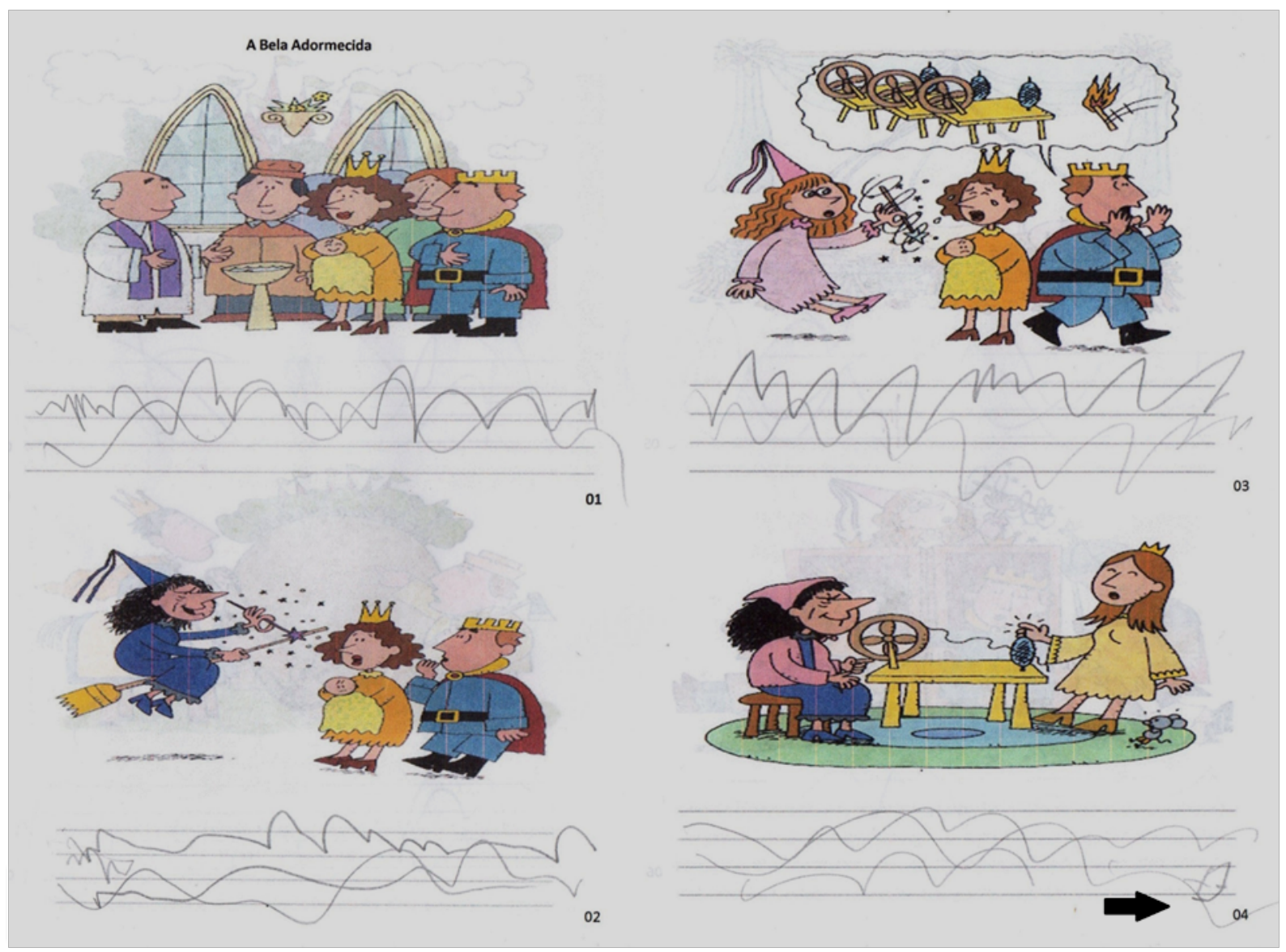

Fonte: Dado coletado pela pesquisadora em 23/04/2018.

Nessa produção, podemos observar o que Borges (2006) diz a respeito da necessidade de a criança representar simbolicamente a linguagem escrita. Isso porque o registro de várias sequências de linhas, em ziguezague, abaixo de cada imagem assinala que a escrita inicial não é pura adequação ao objeto, mas um simulacro que diz respeito à relação do sujeito com o objeto, isto é, da criança com a escrita.

É importante ressaltar que, mesmo sem conhecer ainda as letras da língua constituída, a criança registra uma escrita que para ela tem um valor, quer dizer, os traçados iniciais que simulam o movimento da escrita têm valor de escrita alfabética para a criança, visto que ao concluir sua produção ela afirma ter feito "um monte de lêta" e, em seguida, encena a leitura da narrativa. 
Apontamentos sobre a mudança de posição da criança na sua travessia pela aquisição da escrita Magda Wacemberg Pereira Lima Carvalho

Levando em consideração que escrever, conforme Borges (2006), é uma atividade de imitação das representações do que é possível na escrita, podemos ver que as linhas escritas por $\mathrm{M}$. seguem o mesmo movimento, da esquerda para a direita, assinalando uma sequência sintagmática, além do aparecimento da letra "A" (destacada pela seta) no final dos traçados escritos abaixo da imagem 4.

Ao observarmos os traçados que aparecem na folha, podemos compreender que o valor atribuído pela criança a esse registro tem relação com a representação da escrita que ela vê refletida no papel, isto é, a escrita de traços aparentemente sem sentido figura como textos para a criança. O que nos remete a Bosco (2005) quando ela afirma que na escrita inicial "há um funcionamento próprio da escrita que se faz, no plano gráfico do texto, [...], e que se dá como efeito da relação da criança com textos escritos" (BOSCO, 2005, p. 47).

Um registro que merece destaque é o da letra " $A$ ", escrita no final da página, ocorrência que pode ser entendida, sob o ponto de vista estrutural da mudança, como fragmento dos textos do outro que retorna no texto da criança. Em outras palavras, o aparecimento de uma letra gráfica em uma produção formada por traçados indiferenciados pode indicar o retorno de parte do que a criança vê registrado nos textos que o outro lhe apresenta em situações de leitura e escrita em sala de aula.

Nesse sentido, com fundamento em Lemos (2000; 2002), podemos pensar a emergência da letra " $A$ " como escuta do texto do outro que se apresenta na escrita da criança, indicando a posição em que a criança está alienada ao outro, isto é, o registro de uma letra em meio a traçados, que simulam uma sequência sintagmática, pode ter relação com a alienação da criança à escrita do outro, como quando a criança, referida à fala da mãe, traz para o episódio enunciativo um significante que tem associação com o que foi falado pela mãe. No caso dessa produção, o aparecimento da letra pode ser resultado da presença de uma escrita sobre a qual a 
Apontamentos sobre a mudança de posição da criança na sua travessia pela aquisição da escrita Magda Wacemberg Pereira Lima Carvalho

criança ancora a sua, como as atividades de escrita da "letrinha A" expostas no varal da sala, por exemplo.

Nessa perspectiva, a emergência de uma letra alfabética em meio a traçados pode anunciar que, no movimento de travessia da criança pela aquisição da escrita, o processo de recalcamento do desenho, para ceder lugar às letras alfabéticas, já foi iniciado. Para melhor ilustrar essa posição, observemos a cena a seguir:

\section{Cena 2}

Sabendo que as crianças da turma conheciam diversas histórias, a atividade de produção proposta contou com a mescla de imagens de duas narrativas, a saber, "Chapeuzinho Vermelho" e "Os três porquinhos". Notemos:

Figura 2 - Escrita com formas gráficas diversificadas

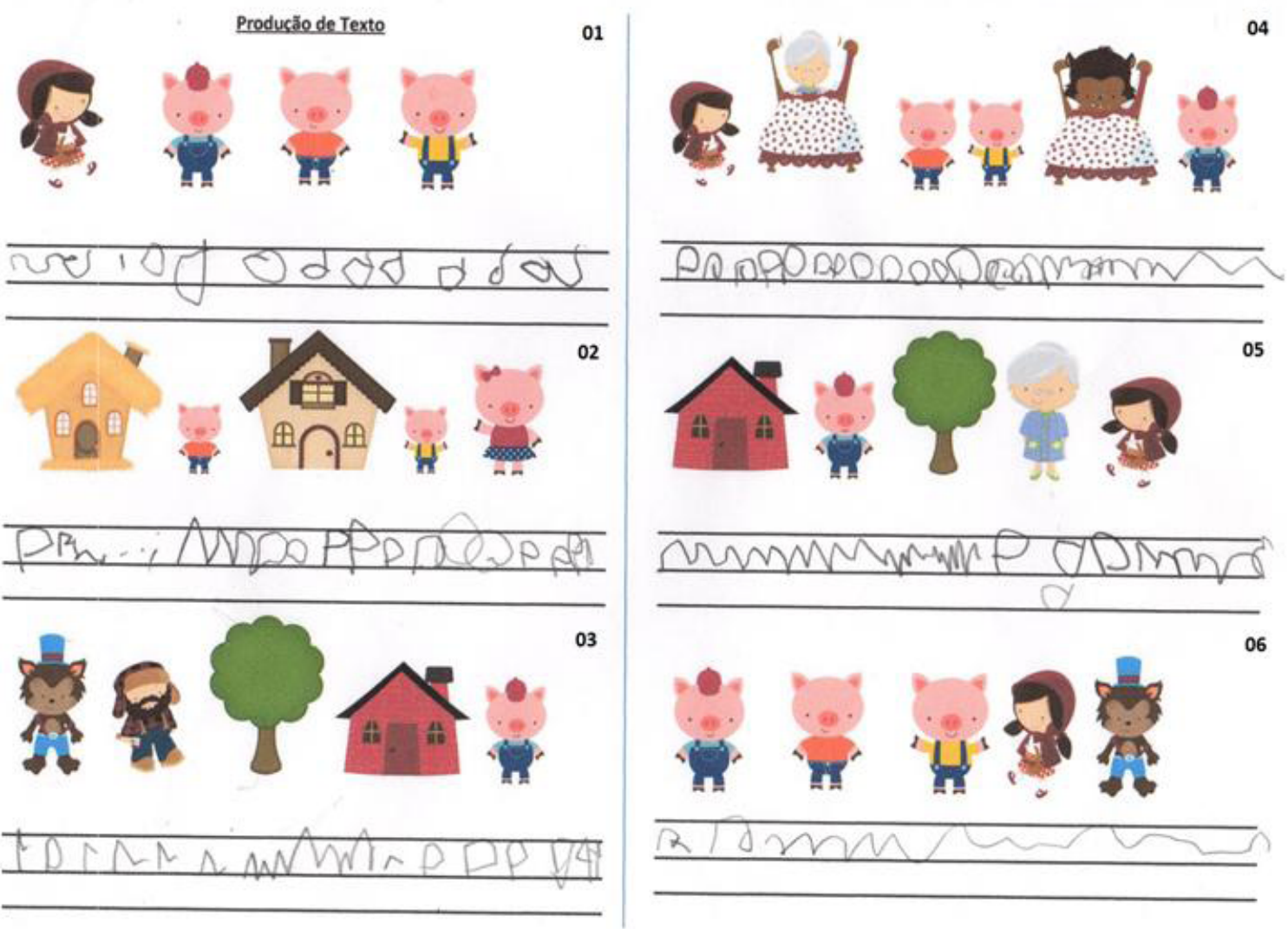

Fonte: Dado coletado pela pesquisadora em 28/05/2018. 
Apontamentos sobre a mudança de posição da criança na sua travessia pela aquisição da escrita Magda Wacemberg Pereira Lima Carvalho

Nessa produção, embora não apareça nenhuma forma gráfica das letras já conhecidas pela criança (letras "A" e "E"), percebemos o registro de pequenos círculos imperfeitos, linhas onduladas e em ziguezague, além da escrita espelhada do numeral 1 (imagem 3).

O que nos chama atenção é o cuidado da menina em escrever linearmente e dentro do limite de espaço disponibilizado entre as linhas dispostas abaixo de cada grupo de imagens. Tal cuidado remete-nos a Borges (2006), quando a autora, ao analisar a escrita inicial das crianças de sua pesquisa, diz que é possível ver um jogo de estruturas complexas em que "as letras aglutinam-se em blocos que se repetem, embora com variações" (BORGES, 2006, p. 129), organizando-se como que em sintagmas com ares de frases. Diante disso, considerando que a inserção de M. no campo da linguagem escrita ainda era recente, concordamos com Bosco (2005) que a interação com textos de natureza diversa é bastante importante para a criança, mesmo quando ela ainda não sabe ler e escrever, pois "a 'captura' da criança pela escrita depende da relação dela com a materialidade dos textos escritos" (BOSCO, 2005, p. 19), quer dizer, no início da travessia pela linguagem escrita é necessário que a criança esteja referida aos textos do outro.

Nesse sentido, pelo movimento de traços que deslizam entre pequenos círculos e linhas onduladas e em ziguezague até a escrita espelhada do numeral 1, podemos observar que esses grafismos, referidos aos textos ofertados pelo outro à criança, dão indícios de que já no início da travessia pela aquisição da linguagem escrita há um funcionamento da língua e que a criança possui um "saber-fazer" sobre/com a escrita.

Para dar maior visibilidade à noção da mudança de posição da criança na estrutura, atentemos-nos para a próxima cena: 
Apontamentos sobre a mudança de posição da criança na sua travessia pela aquisição da escrita Magda Wacemberg Pereira Lima Carvalho

\section{Cena 3}

Essa cena de escrita ocorreu após a aula de revisão das letras "A", "E" e "I", quando a professora da turma distribuiu folhas em branco e solicitou às crianças que escrevessem as letras estudadas. Observemos:

Figura 3 - Desenho e letras

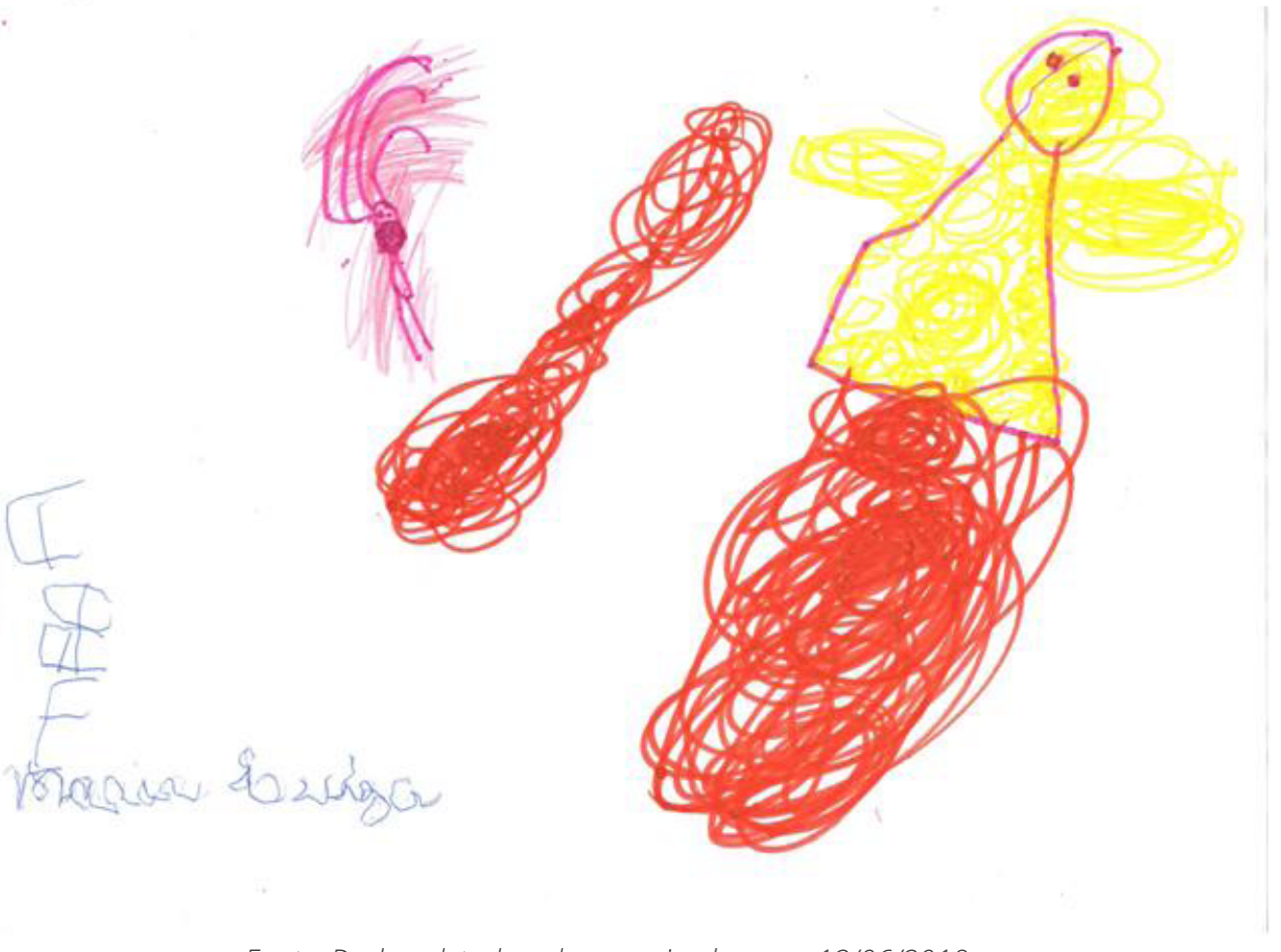

Fonte: Dado coletado pela pesquisadora em 12/06/2018.

Diante da solicitação, M. começa desenhando duas representações do corpo humano e círculos de linhas. Depois, ela pede à professora para escrever seu nome em forma de pontilhado para que pudesse cobrir e, em seguida, escreve uma letra "E" e três letras " $A$ ". Essa cena remete-nos mais uma vez à Borges (2006), quando afirma que "escrever, para a criança, é essencialmente uma atividade de imitação das representações do que é 'possível' na escrita. Por isso, não há ruptura entre os seus atos de escrever e desenhar" (BORGES, 2006, p. 98). 
Apontamentos sobre a mudança de posição da criança na sua travessia pela aquisição da escrita Magda Wacemberg Pereira Lima Carvalho

A esse respeito, acreditamos que, na aquisição da escrita, a travessia da criança se dá num movimento para frente e para trás e, por isso, os registros escritos podem ir do desenho para a letra e da letra para o desenho, uma vez que o movimento de constituição da escrita permite compreender que "a antecedência do desenho sobre a letra é evidente na criança" (POMMIER, 2011, p. 18). Nesse sentido, o aparecimento de desenhos e letras na mesma cena de escrita faz notar que "o desenho e a letra não são duas ordens de grafia separadas, mas a segunda se desarticula da primeira" (POMMIER, 2011, p. 18), quer dizer, o desenho e a letra fazem parte da mesma ordem, mas em algum ponto do movimento de travessia da criança, pela aquisição da escrita, o desenho se separa da letra. Segundo Pommier (2011), isso acontece quando a representação pictórica parece insuficiente para a criança expressar aquilo que ela quer dizer. Então, o valor pictural é recalcado, isto é, o valor da imagem como uma escrita é afastado para dar lugar à letra.

É importante destacar o pedido da criança à professora para que pudesse cobrir o pontilhado do nome. Tal solicitação indica que a escrita das letras que compõem o nome próprio, mesmo não sendo um registro feito pela própria criança, mas pelo outro, "permite a abertura de um lugar particular para a criança como sujeito no campo da escrita: o daquele que escreve" (BOSCO, 2009, p. 57). Nesse caso, o que ganha destaque no gesto dessa escrita é o "movimento gráfico; enquanto marcas sobre o papel" (BOSCO, 2005 , p. 43), visto que a materialidade gráfico-visual do contorno do nome, com valor de assinatura, pode ser considerada indício da inscrição da criança como sujeito no campo da escrita.

Depois de contornar as letras de seu nome, M. diz:

M.: Agora o nome de painho, só fazer assim, pega, dobra, um tracinho.

No momento em que explica o movimento necessário para a escrita do nome de seu pai (iniciado pela letra " $E$ "), a menina começa a fazer a letra " $E$ " maiúscula, seguida de três letras " $A$ " grafadas horizontalmente. Duas ocorrências nos chamam atenção no regis- 
Apontamentos sobre a mudança de posição da criança na sua travessia pela aquisição da escrita Magda Wacemberg Pereira Lima Carvalho

tro dessas letras, a primeira diz respeito ao fato de a menina ter dito que iria escrever o nome do pai e a segunda tem a ver com a grafia horizontal da letra "A".

No que se refere ao registro da letra " $\mathrm{E}$ ", compreendemos que o contato da menina com textos escritos e ofertados pelo outro pode ter feito com que fragmentos desses textos aparecessem na escrita da criança. No entanto, destacamos que o registro dessa letra não compareceu de forma aleatória nessa produção, visto que, antes de grafar, M. anuncia que vai escrever "o nome de painho", o que nos leva a supor que o registro de seu nome na folha convocou a escrita da letra inicial do nome do pai.

Tal pressuposto justifica-se pelo fato de que a escrita do nome próprio, por ser o registro que permite à criança se reconhecer e ser reconhecida no que escreve, pode convocar a criança a escrever letras que formam os nomes daqueles que fazem parte de sua vivência. Nesse sentido, é preciso reconhecer que os textos ofertados à criança funcionam como espelho para ela e, por isso, no movimento inicial de travessia pela aquisição da escrita, as letras que aparecem em sua escrita podem não ser apenas as de seu próprio nome, mas também as letras dos nomes daqueles que figuram como representante do funcionamento da língua.

No que se refere ao aparecimento da letra "A", grafada diferente do previsto pela escrita alfabética, mas figurando como o nome do pai, já que, enquanto escrevia, a menina simulava a leitura do nome do pai, podemos pensar que em decorrência da captura da criança pela escrita esse episódio esteja relacionado ao "erro" e, de modo consequente, à mudança de posição da criança na estrutura.

Nesse caso, entendemos que a grafia de três letras " $\mathrm{A}$ " horizontalizadas e com valor de "E" é resultado da captura da criança pelo funcionamento da língua, logo a posição em que a criança está é aquela cujo polo de dominância é marcado pela língua e seu funcionamento. Cabe repetir que nessa posição a criança está suscetível ao imprevisível da língua, pois as produções linguísticas 
Apontamentos sobre a mudança de posição da criança na sua travessia pela aquisição da escrita Magda Wacemberg Pereira Lima Carvalho

iniciais, na fala ou na escrita, "são cadeias permeáveis a outras cadeias e, portanto, passíveis de deslocamento, de ressignificação, de abrir-se para significar outra coisa" (LEMOS, 2002, p. 61).

Dessa forma, o "erro" que comparece na escrita dessa criança não é acidental, ao contrário, o deslizamento da grafia da letra " $E$ " para a escrita da letra " $A$ " horizontalizada dá a ver, parafraseando Lemos (2000), as relações entre os significantes que circulam na escrita da criança e aponta para o funcionamento da língua.

Passemos, agora, para a próxima cena:

\section{Cena 4}

A produção a seguir foi feita após a leitura do livro "Os três lobinhos e o porco mau"s, tendo sido entregue às crianças da turma uma folha de atividade contendo algumas ilustrações do livro para que escrevessem. É importante destacar que, na época do registro dessa cena, as crianças já conheciam a forma gráfica de quase todas as letras do alfabeto (da letra " $A$ " até a "M"). Vejamos:

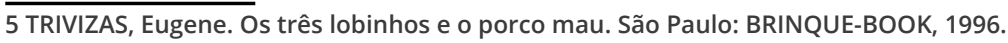


Apontamentos sobre a mudança de posição da criança na sua travessia pela aquisição da escrita Magda Wacemberg Pereira Lima Carvalho

Figura 4 - Escrita com letras
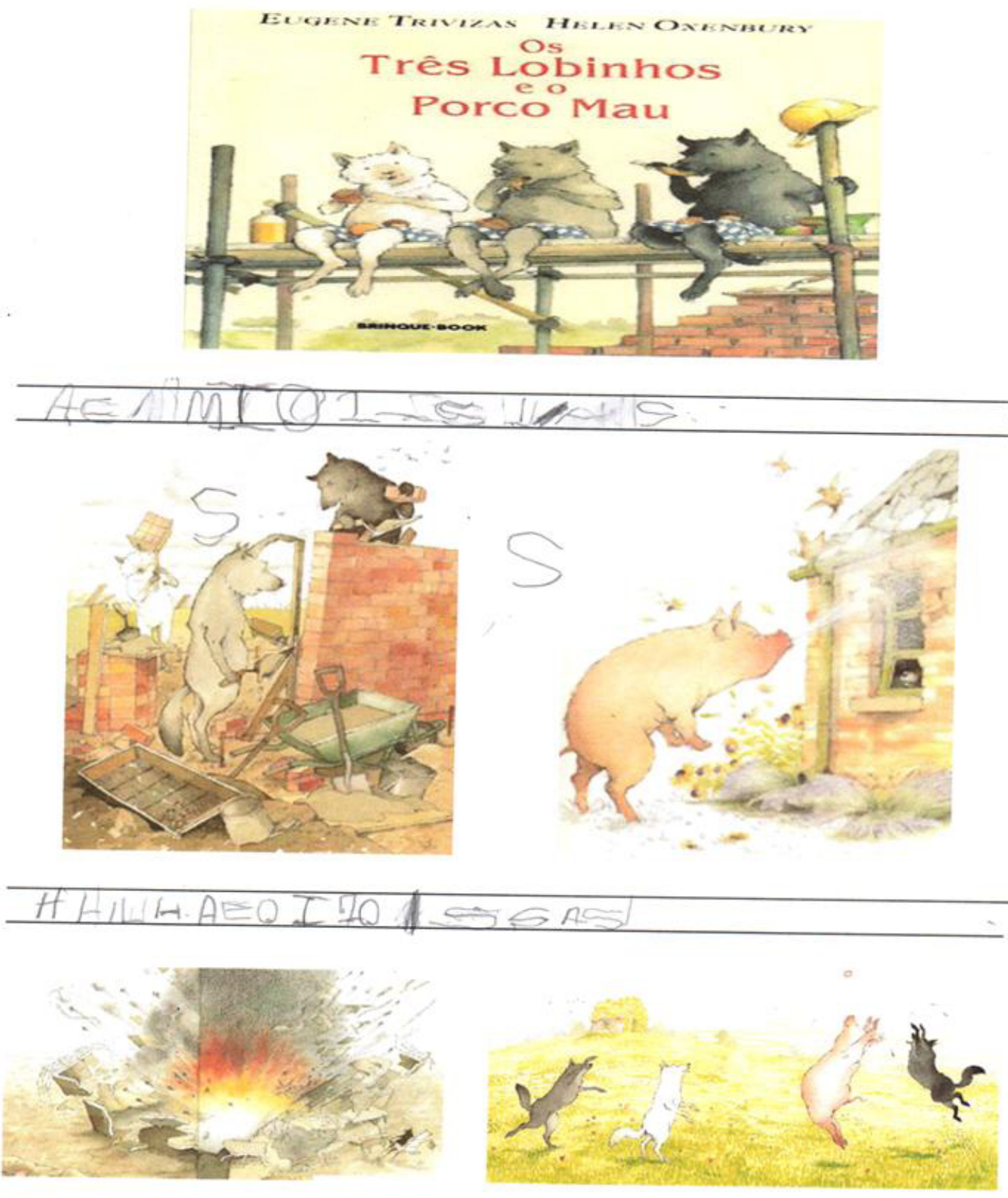

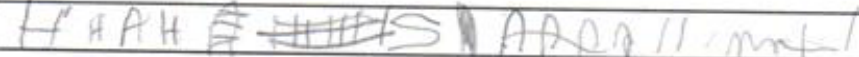

Fonte: Dado coletado pela pesquisadora em 16/10/2018.

Notamos nesse registro que, embora ainda apareçam traçados indiferenciados, M. já escreve algumas letras da língua escrita 
Apontamentos sobre a mudança de posição da criança na sua travessia pela aquisição da escrita Magda Wacemberg Pereira Lima Carvalho

constituída, o que nos leva a afirmação de Borges (2006) de que "escrever com letras, concatená-las, ainda que não seja de acordo com o previsível na língua constituída, indica que o objeto 'escrita' já saiu de uma evanescência imaginária para uma organização possível da escrita" (BORGES, 2006, p. 92).

Nessa cena, ao receber a atividade e depois de observar todas as imagens, M. escreve a letra " $A$ " e em seguida diz à pesquisadora, P.:

M.: Ó num tem esse traço? Joga pra cá, depois pra cá, pra cá, aí depois pra cá (fala enquanto escreve a letra "E").

P.: O que você escreveu aí?

M.: Edenildo José meu pai. Ó tu qué vê ó a minha (letra)?

P.: Aham.

M.: Ó num tem esse tracinho aqui? Ó você puxa, bota pra baixo aí sobe pra cima e ó (fala enquanto escreve a letra "M"). Essa eu errei, eu errei o meu (apaga e escreve novamente). Errei também (apaga mais uma vez a letra escrita). Pronto! Ficou bom. Vô fazê ôta dessa merma (escreve mais uma consoante "M"). Aquela bolinha (faz movimentos circulares com o lápis no ar). Aquele tracinho ó tan pra trás (faz movimento como se estivesse escrevendo um traço e escreve na folha as letras "O" e "I"). Ó tan pra cá, tan pra cá e tan pra cá (fala enquanto faz o gesto da escrita do traço). Num tem aquela bem gordona?

P.: Qual?

M.: Assim ó (escreve duas letras "S" próximo às ilustrações e mais duas nas linhas).

E assim, no primeiro segmento escrito, temos as letras: " $A$ ", " $E$ ", “M" (traçado apagado), “M", “I”, “O”, “I”, "I", “S", “I”, “A” (traçado apagado) e " $S$ ". O que nos chama atenção nessa sequência de letras é que a criança, apesar de já conhecer a grafia de outras letras do 
Apontamentos sobre a mudança de posição da criança na sua travessia pela aquisição da escrita Magda Wacemberg Pereira Lima Carvalho

alfabeto, inicia sua produção escrevendo as letras " $A$ " e " $E$ ", que frequentemente apareciam registradas nas atividades propostas no início de seu movimento de travessia pela escrita. No entanto, M. agora escreve explicando, detalhadamente, o movimento do lápis para cada registro, como no caso da letra "E", que a partir do traço de uma linha vertical, ela "joga pra cá, depois pra cá, pra cá, aí depois pra cá" para fazer as três linhas horizontais que dão forma à letra.

Ao perguntarmos o que havia escrito, M. fala o nome de seu pai e pergunta se queremos ver o dela. Ao receber resposta afirmativa, ela novamente começa a explicar como a letra é escrita e, enquanto anuncia o percurso do lápis sobre o papel, escreve a letra "M", confirmando o que Bosco (2005) diz a respeito de as letras do nome serem as que fornecem à criança elementos de uma relação com a escrita que não passa, necessariamente, pela fonetização, mas pela relação de representação.

Ao observar que o traçado não havia ficado de acordo com sua expectativa, M. atenta para o que considera "erro" - "eu errei o meu" -, apaga a letra e escreve novamente. Ao avaliar, depois, que o traçado não havia ficado bom, ela escreve outra letra " $M$ ", dessa vez sem indicar o percurso do traço. Nesse momento, quando diz que "errou" a letra, podemos pensar essa cena como representativa da posição marcada pela dominância do sujeito. No caso da escrita, com base no que Lemos (2002) reflete sobre a aquisição da fala, poderíamos dizer que se refere à posição em que a criança, como escrevente, se divide entre aquele que escreve e aquele que reconhece sua própria escrita, "sendo capaz de retomá-la, reformulá-la" (LEMOS, 2002, p. 56). Nesse sentido, o reconhecimento da imprecisão do traço que constitui a letra, ao suscitar tentativas de correção/reformulação do registro, sinaliza que "a criança é capaz tanto de reconhecer quanto de corrigir erros" (LEMOS, 2006, p. 30) em sua produção.

Após refazer a escrita da letra " $\mathrm{M}$ ", a menina segue escrevendo, mas sem associar o nome da letra à forma gráfica. Um dos momentos surpreendentes foi quando ela fez a pergunta: "num tem 
Apontamentos sobre a mudança de posição da criança na sua travessia pela aquisição da escrita Magda Wacemberg Pereira Lima Carvalho

aquela bem gordona?" e sem sabermos de que letra se tratava, a criança faz surgir em sua produção duas letras "S". Nossa surpresa em relação ao aparecimento dessa letra se dá em razão de essa ser uma das últimas letras do alfabeto que seria apresentada às crianças da turma, mas M. já conseguia escrevê-la.

Nesse sentido, apesar de a escrita de M. ainda não se apresentar em conformidade com o previsto pela escrita constituída, o comparecimento, em sua produção, de diferentes letras aponta para isso.

Borges (2006) diz que à medida que nos tornamos mais sensíveis à escrita inicial podemos ver um jogo de estruturas complexas, cuja organização das letras implica certa ordem, "não a que regula a escrita constituída, mas a presidida pelas leis do significante" (BORGES, 2006, p. 130), como vemos, por exemplo, em " $\mathrm{H}$ ",

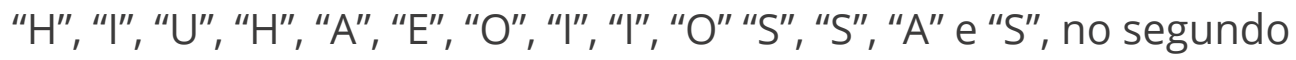
grupo, e " $H$ ", " $A$ ", " $A$ ", “ $H$ ", " $S$ " mais alguns traços incompreensíveis, no terceiro grupo.

Diante disso, reconhecemos que a passagem do traçado para o desenho e deste para a letra, na travessia da criança pela aquisição da linguagem escrita, implica, como disse Borges (2006), que a criança represente a língua escrita. Dessa forma, o contato com a materialidade dos textos é essencial, pois são esses textos que dão a ver a mudança de posição da criança na estrutura e que, como espelho, orientarão a travessia da criança na passagem de não-escrevente para escrevente.

\section{Considerações Finais}

Cabe aqui retomar, em poucas palavras, o objetivo principal deste trabalho: observar o movimento de travessia da criança pela aquisição da linguagem escrita, a partir da visão estrutural da mudança de posição do sujeito, em relação ao outro, à língua e ao próprio sujeito para compreender como os rabiscos cedem lugar aos desenhos e esses à letra gráfica. 
Apontamentos sobre a mudança de posição da criança na sua travessia pela aquisição da escrita Magda Wacemberg Pereira Lima Carvalho

Parece-nos conveniente realçar que, para que a criança chegue até a escrita com letras alfabéticas, o contato com textos de natureza diversa é imprescindível, pois, como foi possível observar, a materialidade dos textos foi fundamental para o aparecimento da letra gráfica no movimento de travessia, iniciado por M., pela aquisição da linguagem escrita.

Ao supormos que a letra propriamente dita surge na escrita inicial quando a criança, capturada pelo funcionamento linguístico-discursivo da escrita, movimenta-se na estrutura e recalca a representação pictórica para dar lugar à letra, observamos, no caso de M., que as letras surgem como efeito do apagamento da representação figurativa. Isso porque a menina inicia escrevendo sequências de linhas em ziguezague, pequenos círculos imperfeitos, linhas onduladas, escrita espelhada de letras e números, desenho de representação do corpo até chegar à escrita de letras.

Nessa perspectiva, a emergência da letra " $A$ " entre os traçados de linhas, que lembram a organização gráfica de um texto escrito, dá a ver o recalque que sustenta a passagem do desenho à escrita alfabética, ou seja, o aparecimento de uma letra em meio aos grafismos e traçados na escrita inicial da criança indica que o processo de recalcamento da representação pictórica já foi iniciado, sendo possível, então, haver a passagem do desenho para a letra.

Diante disso, acreditamos que nossa tentativa de colocar em discussão o movimento de travessia da criança pela aquisição da escrita, a partir de uma proposta teórica que entende a aquisição de linguagem não como resultado de estágios de desenvolvimento, mas como algo que decorre das mudanças de posição da criança na estrutura, permitiu-nos observar que os registros gráficos da criança, em aquisição da escrita, mostram-se abertos a múltiplas transformações e que a criança referida ao outro poderá apresentar em sua escrita fragmentos de textos desse outro, bem como registros indicativos de erros de não-saber, além de tentativas de correção/reformulação de seus registros quando ela (re)conhece o erro. 
Apontamentos sobre a mudança de posição da criança na sua travessia pela aquisição da escrita Magda Wacemberg Pereira Lima Carvalho

Nesse sentido, reiteramos nossa compreensão de que na travessia da criança pela aquisição da linguagem escrita os traçados cedem lugar aos desenhos e esses à letra gráfica quando a criança, capturada pelo funcionamento linguístico-discursivo da escrita, movimenta-se na estrutura e recalca a representação pictórica.

Para finalizar, reconhecemos que a discussão acerca da aquisição da linguagem escrita não se esgota neste trabalho e nem no caso apresentado, uma vez que há diferentes formulações teóricas para abordar o tema e que cada criança faz sua travessia pela escrita de maneira singular. No entanto, considerando que "é o ponto de vista que cria o objeto" (SAUSSURE, 2006, p. 15), o interacionismo brasileiro, em especial a noção estrutural de mudança de posição, foi o ponto de vista que assumimos para investigarmos a mudança de estatuto da criança de não-escrevente para escrevente, no campo da aquisição da linguagem escrita.

\section{Referências}

BORGES, Sônia. O quebra-cabeça: a alfabetização depois de Lacan. Goiânia: Ed. da UCG, 2006.

BOSCO, Zelma Regina. A criança na linguagem: a fala, o desenho e a escrita. São Paulo: Cefiel/IEL/UNICAMP, 2005.

BOSCO, Zelma Regina. A errância da letra: o nome próprio na escrita da criança. Campinas, SP: Pontes Editores, 2009.

BURGARELLI, Cristóvão Giovani. Escrita e corpo pulsional. 2003. $126 f$. Tese (Doutorado em Linguística) - Universidade Estadual de Campinas, Instituto de Estudos da Linguagem, Campinas, SP, 2003.

CHEMAMA, Roland. Dicionário de psicanálise. Porto Alegre: Artes Médicas Sul, 1995.

JAKOBSON, Roman. Linguística e Comunicação. 21.ed. São Paulo: Editora Cultrix, 2008. 
Apontamentos sobre a mudança de posição da criança na sua travessia pela aquisição da escrita Magda Wacemberg Pereira Lima Carvalho

LEMOS, Cláudia Thereza Guimarães de. Uma abordagem sócio-construtivista da aquisição de linguagem: um percurso e muitas questões.

Anais do I Encontro Nacional sobre Aquisição de Linguagem, CEAAL, PUCRS, 1989. p. 1-14.

LEMOS, Cláudia Thereza Guimarães de. [1992] Os Processos Metafóricos e Metonímicos como Mecanismos de Mudança.

Substratum/ Artes Médicas, v. 1, n. 3, p. 151-172, 1998.

LEMOS, Cláudia Thereza Guimarães de. Sobre a aquisição da escrita: algumas questões. In: ROJO, R. Alfabetização e letramento: perspectivas linguísticas. Campinas, SP: Mercado das Letras, 1998. p. 8-18.

LEMOS, Cláudia Thereza Guimarães de. Sobre o "Interacionismo".

Revista Letras de Hoje, v. 34, n. 3, p. 11-16, set. 1999. Disponível em: http://revistaseletronicas.pucrs.br/ojs/index.php/fale/article/ view/14944/9884. Acesso em 10 maio 2018.

LEMOS, Cláudia Thereza Guimarães de. Desenvolvimento da Linguagem e Processo de Subjetivação. Revista Interações, v. V, n. 10, p. 53-72, jul/dez. 2000. Disponível em: https://www.redalyc.org/ pdf/354/35401004.pdf Acesso em: 11 maio 2020.

LEMOS, Cláudia Thereza Guimarães de. Das Vicissitudes da Fala da Criança e sua Investigação. Cadernos de Estudos Linguísticos. Campinas: IEL/ Unicamp, n. 42, p. 41-69, 2002. Disponível em: https://periodicos.sbu.unicamp.br/ojs/index.php/cel/article/view/8637140. Acesso em: 10 jun. 2020.

LEMOS, Cláudia Thereza Guimarães de. Uma crítica (radical) à noção de desenvolvimento na Aquisição da Linguagem. In: LIER-DE VITTO, Maria Francisca; ARANTES, Lúcia (org.). Aquisição, patologias e clínica de linguagem. São Paulo: EDUC, FAPESP, 2006. p. 21-32.

POMMIER, Gérard. Naissance et renaissance de l'écriture. Paris: Press Universitaires de France, 1993.

POMMIER, Gérard. A história da escrita e a aprendizagem de cada criança. In: LIER-DE VITTO, M. F.; ARANTES, L. (org.). Faces da escrita: linguagem, clínica, escola. Campinas, SP: Mercado de Letras, 2011. p. 17-31.

SAUSSURE, Ferdinand de. [1916] Curso de Linguística Geral. 27.ed. São Paulo: Cultrix, 2006. 